\title{
ARQUEOLOGIA URBANA EN VALENCIA: UNA JARRITA CON TEXTO POÉTICO *
}

\author{
Por \\ JOSEP VICENT LERMA \\ $Y$ \\ CARMEN BARCELÓ \\ * Este trabajo se presentó como comunicación (con el título "Arqueología urbana en Valencia: una \\ jarrita con texto poéticon) a las //I Jornadas de Cultura Árabe e /slámica (Madrid. IHAC, mayo de
} 19831

Los trabajos arqueológicos realizados por el Servicio de Investigación Arqueológica Municipal (SIAM) en la ciudad de Valencia, a partir de 1981, han permitido recuperar una importante cantidad de cerámicas de época islámica. Entre ellas, tiene una especial importancia la pieza procedente de la excavación realizada en la calle del Mar, números 23-25, que ahora presentamos (1). Se trata de una jarrita con decoración esgrafiada sobre manganeso, cuyo estado de conservación es bueno, faltando únicamente el extremo del borde. Tal circunstancia encuentra su explicación en el propio contexto arqueológico del haliazgo, ya que fue documentado formando parte del relleno de un profundo pozo, de los que abundaban en esta ciudad para el abastecimiento doméstico de agua, los cuales eran utilizados como basureros una vez dejaban de cumplir su primera función. Junto a la misma, fueron encontradas jarritas de cuerda seca parcial, braseros de pared calada, ataifores monocromos, dos plaquetas de hueso con decoración epigráfica, cerámica de cocina, etcétera.

A continuación, pasamos a realizar la descripción de la jarrita objeto de nuestro estudio (fig. 1, láms. I y II). Formalmente, es similar a lo que venimos denominando tipo l (2). Presenta el pie en forma de anillo, con el centro convexo; panza ligeramente ovoide con una arista a la altura de la inserción de las asas, bien marcada en algunos puntos; cuello troncocónico, más abierto junto a la boca que en su arranque; dos asas verticales, con fuerte acanaladura longitudinal y apéndice cónico, aplicadas desde el cuello a la panza.

(1) RIBERA, A. y LERMA, J. V., «Excavaciones arqueologicas en la calle del Marn, Boletin de Información Municipal, núm. 31, noviembre de 1981, Valenciá, pp. 14-15

(2) LERMA. j. V.; MIRALLES, I., y SOLER, M. P., "Cerámicas musulmanas de "El Tossalet de Sant Esteve". Valencian. "l Coloquio Internacional de Ceramica Medieval del Mediterráneo Occidental, Toledo, 2-7 de noviembre. 1981 ien prensal. 
Sus dimensiones son las siguientes: altura conservada, 14 centimetros; diámetro máximo 12.5; diámetro base, 6 ; espesor, 2.5 milímetros

La decoración muestra, sobre la cara externa, un tema iconográfico consistente en tres bandas horizontales de signos epigráficos árabes sobre fondo de espirales esgrafiadas, de las cuales, dos se emplazan sobre la panza y una sobre el cuello. Completa la composición otra banda horizontal, esta vez de tema geométrico, situada en el inicio del cuello. Sobre las asas, aparecen dos líneas de manchas de manganeso.

En relación con todo ello, hay que remarcar el modo en que el soporte condiciona la distribución de los registros decorativos, interrumpiéndolos en unas ocasiones (bandas superiores del cuello y de la panza) y obligando a cortar las letras en otras (banda inferior de la panza) (fig. 2).

En cuanto a las características tecnológicas, conviene señalar que la arcilla empleada es fina, de color amarillento, y con escasas inclusiones calizas. Por otra parte, las huellas de un círculo existente alrededor del anillo del pie, por debajo de la decoración, viene a resolver el modo de apilamiento de estas piezas dentro del horno para su cocción: esto es, introduciendo la base en la boca de la inferior o viceversa.

La nota más sobresaliente de esta pieza cerámica es la importancia que el artesano ha dado a la decoración epigráfica, en detrimento de la geométrica o vegetal, cuya utilización suele ser mayor en objetos como el presente. No se trata, por otra parte, de un caso insólito. Un precedente podría ser el tintero de brance de Corberes. Por lo demás, existen noticias sobre composiciones poéticas destinadas al adorno de piezas metálicas, como el poema escrito por ibn alŶayyâb para un jarrón o acetre (sațl) del sultán granadino Ismacîl | (3).

El texto de la jarrita de la calle del Mar se desarrolla en seis pequeños tarjs tones cuyo contenido tiene sentido en si mismo, de modo que el espectado, puede detenerse en cualquiera de sus fajas o bien leer tres lineas de una cara, sin que ello perturbe las expresiones acabadas en cada una de ellas o las que están en la cara contraria. En el restablecimiento del texto que aqui se propone no se advierten restos o cadencias rítmicas, ni tampoco rima poética. La lectura que proponemos, comenzando por la cara donde falta una parte de escritura, es como sigue:
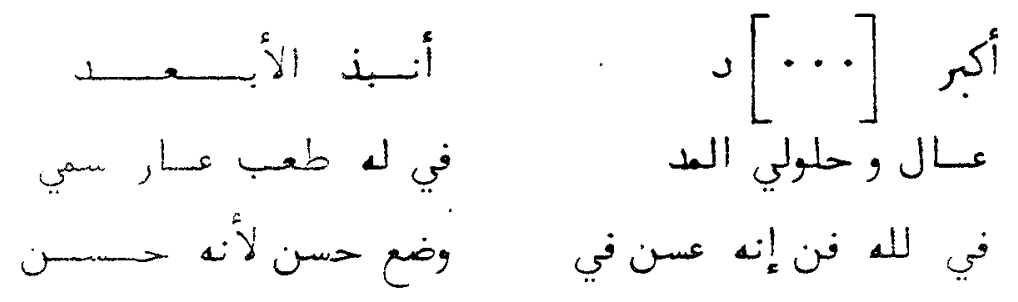

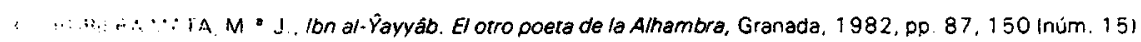

, 
- Boca: «|Glorifica a Dios por [...]! ¡Rechaza lo más alejado!»

- Banda media: "Es algo excelente pues mis resultados están al alcance de la vista. Mi boca tiene un gusto agradable, está exenta de defectos, es sublime.n

- Banda inferior: «En mí, ipor Dios!, hay un arte que en mí tiene hermosura. El poner Allăh [Dios] es bueno porque Él es excelente."

Desde el punto de vista epigráfico, el texto presenta su trazado en letras nasjies, sin vocalización ni puntos diacríticos (fig. 3). A pesar del carácter provisional de la lectura, parece que el artífice entendía lo que grababa y dio a los caracteres cierta elegancia y esbeltez. En la banda inferior se advierte el apéndice de $w a ̂ w$ (en $w a d^{c}$ ), aunque la cabeza ha desaparecido como si al aplicar el asa aquélla quedara escondida tras ésta (fig. 2).

Por lo que se refiere a la decoración floral, que aparece rellenando algunos huecos dejados en el desarrollo epigráfico, se reduce a palmetas, atgunas de ellas con incisiones, y ciertas formas que recuerdan botones o discos (4). En cuanto a los adornos geométricos, sólo aparecen en una banda que separa la primera cinta epigráfica, junto a la boca, de la segunda, y está situada junto al inicio del cuello. No hemos encontrado paralelos y exactos, pero parece tratarse de una cadeneta con reminiscencias rómbicas $(5)$.

Por todo lo dicho, es posible que la fuente de inspiración del ceramista fuera un modelo en metal, como el precedente ya citado, por lo que se refiere al estilo literario, del tintero de bronce de Corberes (Rosellón) (6). En este sentido. tal vez los apéndices cónicos sobre las asas podrian ser un trasunto de primitivos remates metálicos.

Con todo, creemos encontrarnos ante un objeto cerámico de fabricación local, posiblemente en la misma línea de lo ya apuntado por Zozaya sobre la existencia de varios centros productores en torno a Valencia (7).

Las jarritas, con decoración esgrafiada de tema epigráfico, nos consta que son frecuentes en la zona murciana, si bien se trata generalmente de un concepto único o de frases cortas. Del mismo estilo, se conocen igualmente en la ciudad de Denia (Alicante). Por el contrario, la pieza que nos ocupa responde a otros presupuestos, que hasta ahora sólo encuentran un posible paralelo en una de las jarritas del alfar mallorquín de Zavellà.

Para nosotros, la cronología de esta pieza se sitúa hacia finales del siglo Xझ o principios del XIII, teniendo en cuenta, además, la imposibilidad de considerarla más reciente, por cuanto la fecha del 1238 , año de la conquista de la ciu-

(4) Cfr. PAVON MALDONADO, B., El arte hispano-musuimán en su decoración floral, Madrid, 1981.

(5) Aunque sólo recoge material arquitectónico, cfr. PAVON MALDONADO, B., El arté hispano-musulmán en su de coreción geométrica, Madrid, 1975.

(6) ALMAGRO, M., "El tintero árabe califal de la íglesia de Corberes (Rosellón /m, crónica del VIII Congreso Arqueo/ó gico Nacional, Zaragoza, 1964, 487-490; GALVEZ, M. E., "Consideraciones sobre la inscripción del tintero árabe califal de la iglesia de Corberes (Rosellón)*, Boletin de ia Asociación Española de Orientalistas $11,(1966)$, pp. $192-196$.

(7) ZOZAYA, J., "Aperçu général sur la céramique espagnolen, Colloques Internationaux, C. N. R. S. núm. 584, La céramique Médiévale en Méditerranée Occidentale, París, 1980, p. 283, nota 85. 
dad por los catalanes y aragoneses del rey Jaume l, señala el momento final del dominio islámico en Valencia.

La importancia de este hallazgo radica en la posibilidad, frecuentemente negada al arqueólogo, de trascender el objeto en sí mismo, para adentrarnos en el ámbito de la ideología de una sociedad desaparecida hace siglos de las tierras valencianas. 

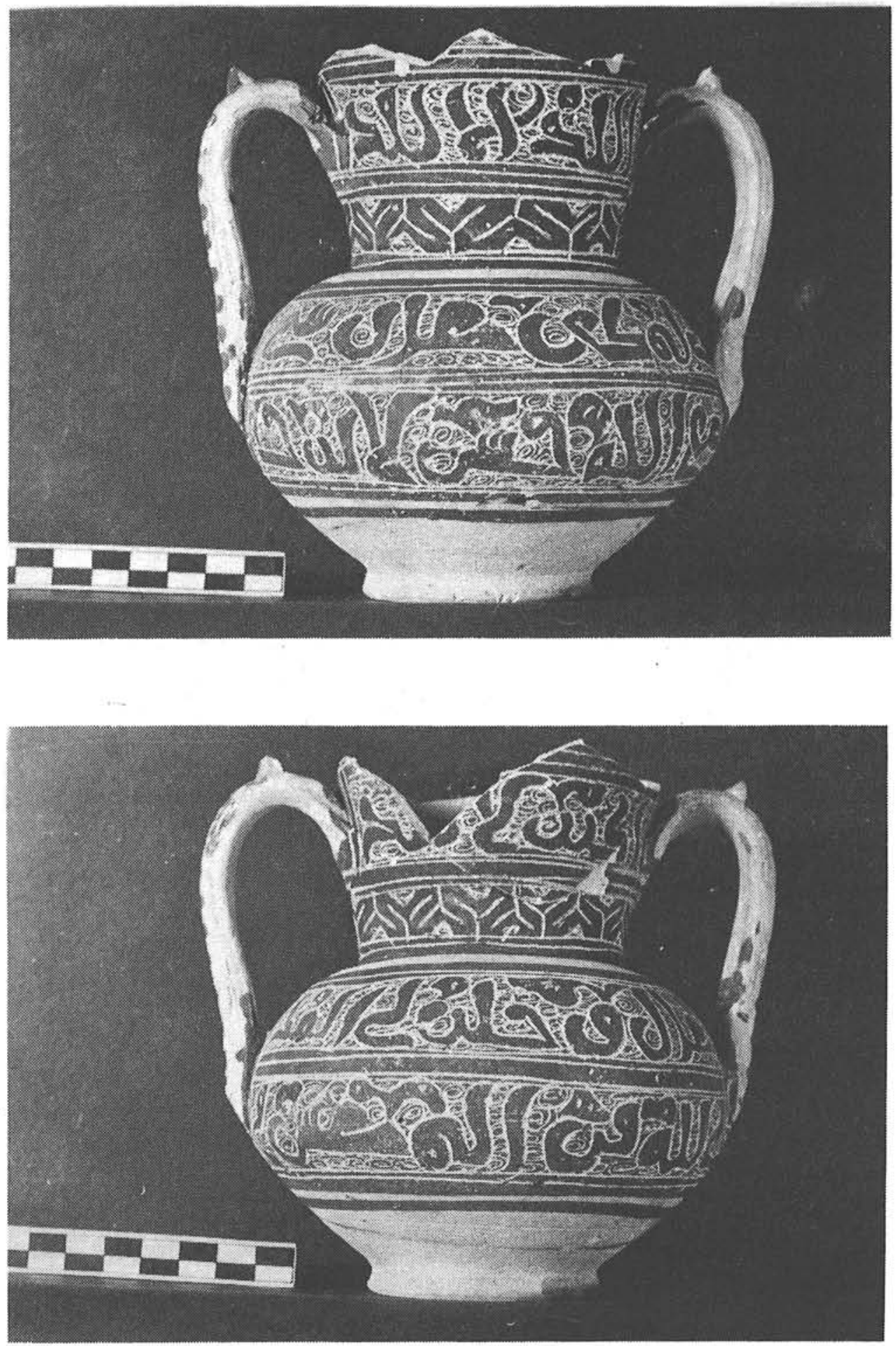


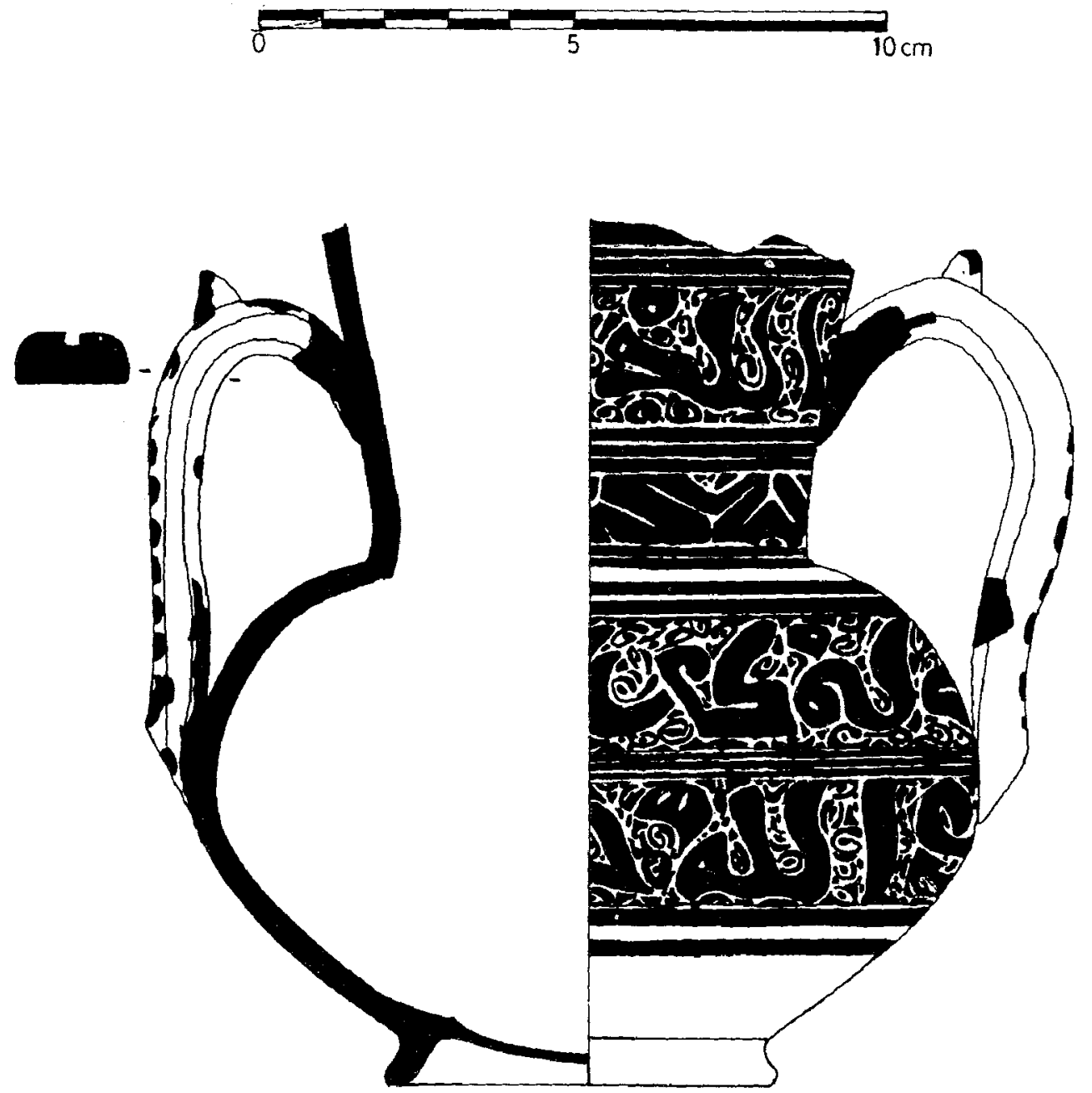

\section{3 ind

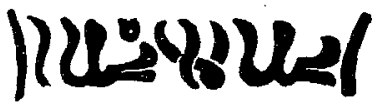

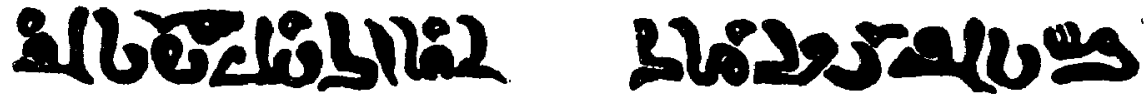

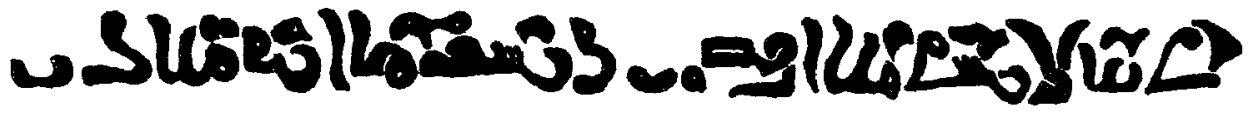




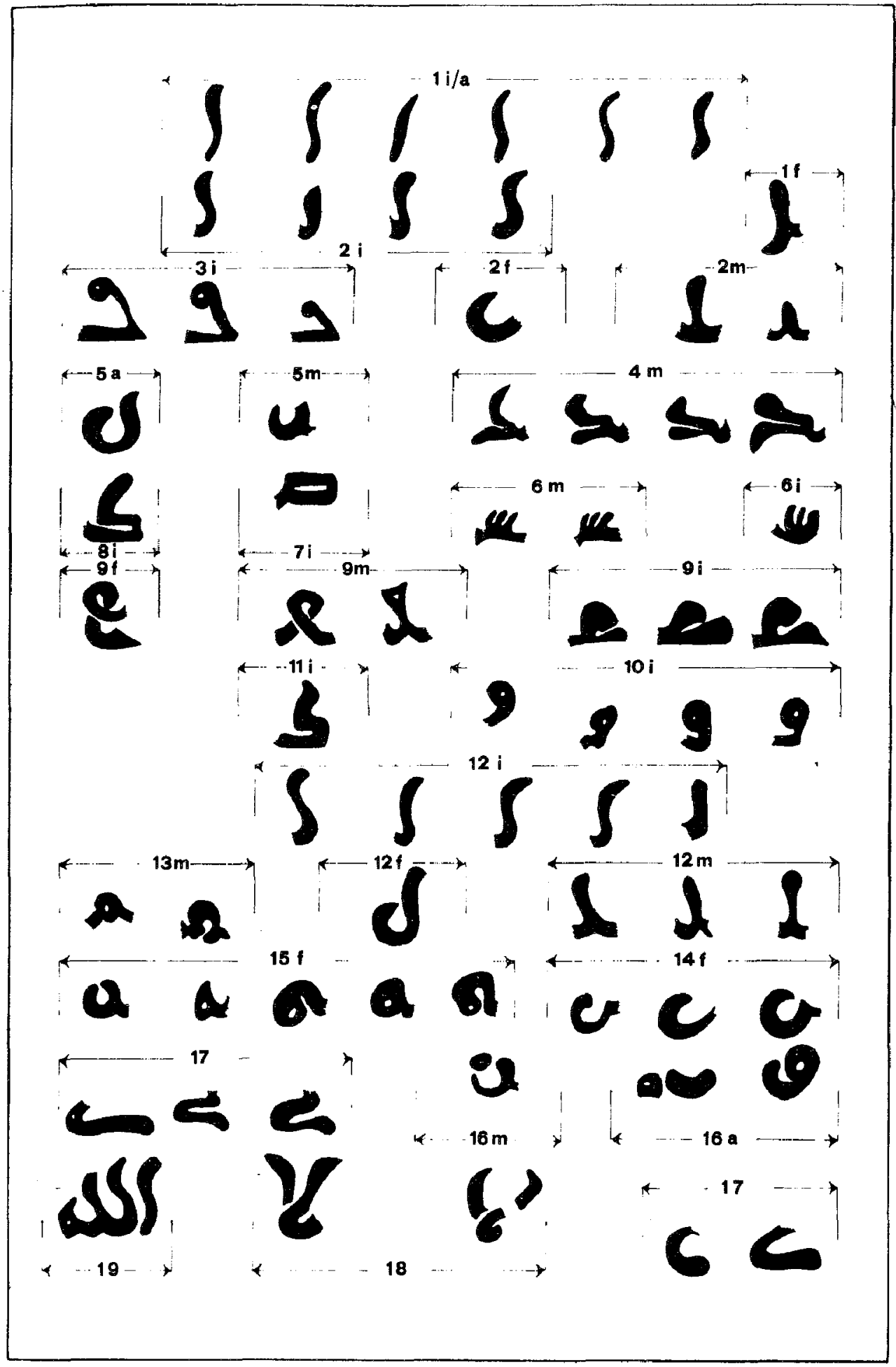

